\title{
SLEEP APNEA, PULMONARY HYPERTENSION AND NEPHROTIC SYNDROME*
}

\author{
By Bashir A. Chaudhary, M.D. Asserciate Professor of Medicine \\ Allen J. Dennis, M.D., Professor of Medicine \\ Tesneem K. Chaudhary, M.D., Fellow, Allergy-Immunology \\ William A. Speir, M.D., Professor of Medicine \\ From the Department of Medicinc, Medical College of Georgia, Augusta, Georgia
}

\begin{abstract}
Summary
Many cardiopulmonary abrormalities have been described in patients with sleep apnea syndrome. We are reporting a patient with severe obstructive sleep aprea who had severe episodic pulmonary hypertension, hypoxemia. and nephrotic syndrome. We are postulating that nephrotic syndrome was causally related to sleep aprieas.
\end{abstract}

Introduction

Sleep-apnea syndromes are characterized by obesity, excessive daytime somnolence, snoring, and many episodes of apneas at night'. 'Apneic episodes may cause pulmonary hypertension and right heart failure (Pickwickian syndrome). Repeated episoder of acute pulmonary edema and many other cardiovascular abnormalities may sccur in patients with sleep apnea syndrome ? 3 . Hypoxemia and pulmonary hypertension have been implicated in the pathogenesis of pulmonary edema in patients with slexp apnea. It is likely that hypoxemia and pulmonary hypertension (and consequent systemic venous hypertension) may lead to dysfunction of other organs. We report a patient with sleep apnea syndrome who had severe episodic noctumal pulmonary hypertension and was found to have nephrotic syndrome.

\section{Case Report}

A 29 -year-old white male was refersed to the sleep disorder center of the Talmadge Memorial Hospital Medical College of Ceorgia (TMH-MCG) for evaluation for sleep apnea syndrome.

The patient weighed 180 lhs. at 22 years of age when he started gaining weight and during the next seven years his weight increased to 347 pounds. He began having progressive daytime sumnolence and shortness of breath four years prior to his evaluation at TMH-MCG. The patient had fallen asleep many times: during conversation, eating his foud. driving the car, and during other activities. He had quit his job because of his inability to stay awake. His shortness of breath had been mainly at night; he would get up on multiple occasions each night with a choking sensation and struggling for breath. Many times, the patient had spent the whole right sitting to relieve his shortness of breath. During the two years prior to this evaluation, he started having swelling of his legs and progressive shortness of breath with exertion. He also had a history of loud snoring. The patient was admitted to his local hospital on multiple occasions because of shortness of breath. During thase hospitalizations, no evidence of cardiac disease was found. He had high hemoglobin level (up to $21 \mathrm{G} / \mathrm{dl}$ ), hypoxemia $\left(\mathrm{PaO}_{2}\right.$ in 405 ) and 3 to $4+$ proteinuria during these hospitalizations. The patient was being treated with a diuretic, bronchodilators and digitalis.

When evaluated at the TMH-MCG pulmonary clinic, the patient was extremely drowsy, and fell asleep many times during the interview, but was not in acute distress. His blood pressure wiss $128 / 90 \mathrm{mmHg}$, respiration $20 /$ minutes, and he weighed 326 pounds. The remainder of the physical examination was normal except for slight edema of his lower legs. Pulmonary function tests showed mild restrictive ventilatory impairment and the arterial blood gases showed hypoxemia $\left(\mathrm{PaO}_{2} 52 \mathrm{mmHg}, \mathrm{SaO}_{2} 78 \%\right)$ and hypercapnia $\left(\mathrm{PaCO}_{2} 48 \mathrm{mmHg}\right)$. The patient was admitted to the TMH-MCC for further work up and treatment.

Urinalysis showed specific gravity of $1,024,4+$ prolteinuria, oval fat bodies, and maltese crosses - all characteristic of nephrotic syndrome. Twenty-four hour urine excretion of protein was $4.5 \mathrm{G}(84 \%$ albumin on protein electrophoresis). The creatinine clearance was $119 / \mathrm{ml} / \mathrm{min}$. No other evidence of renal abnormality was found.

A Swan-Ganz catheter was inserted to monitor pulmonary artery pressure. In the awake state, the pulmonary artery pressure was 44/22 $\mathrm{mmHg}$ (mean 33 $\mathrm{mmHg}$ ). The catheter could not be wedged in the pulmonary artery and hence the wedge pressure could not be obtained. The pulmonary artery pressure repeatedly increased during the apneic episodes and reached a level as high as $152 / 72 \mathrm{mmHg}$ (mean 100 $\mathrm{mmHg}$ ). In addition, the patient conghed many times during sleep. During these coughing episodes the pulmonary artery pressure showed further clevations and maximal systolic pulmonary artery pressure of 320 $\mathrm{mmHg}$ was recorded. The patient had an arterial line to monitor systomic arterial pressure, and arterial pressure remained in the normal range (110/70 - 122/80 $\mathrm{mmHg}$ ) during the episodes of pulmonary artery hypertension. Radionuclear ventriculography with $99 \mathrm{mTC}-\mathrm{PY}$ showed a left ventricular ejection fraction of $66 \%$ and a right ventricular ejection fraction of $18 \%$. In addition, paradoxical motion of the interventricular septum was noted during each systole.

A six hour nocturnal polysomnographic recording of electroencephalogram, chest wall and abdominal expansion, airflow at the mouth and nastrils, and oxygen 
saturation was made. The patient awakened repeatedly, many times coughing, bul fell aslexep again. He spent 2 hours and 19 minutes in sleep during the study and had 193 apneic episodes. The apneic episodes varied from 10-36 seconds in duration (mean 18.5 seconds). His apnea irıdex (number of apneas/hour of sleep) was 45 and he spent $43 \%$ of his sleep tine in an apneic state. All of these apneic cpisodes were sbstruclive in type, i.c., the chest wall and abdominal expaysion continued during the apneic episodes (Fig. 1). The oxygen saturation was $95 \%$ at the beginning of the study, but fell repeatedly; the lowest oxygen saturation was $26 \%$ following a 36 sexund apneic episode. He had occusional premature cardiac beats, but no serious arrhythmias were noted.

The patient underwent tracheostomy. His postoperative coursc was uneventful. The daytime somnolence and shork nex of breath slowly improved over the next few weeks.

\section{Discussion}

In patients with obstructive sleep apnca syndromes, many pulmonary, cardiovascular, neurnlogic and psy'chíatric problems have been described. We have not seen any' reports describing renal abnormalities in putients with slecp apnea syndromes. We believe this is the first report of nephrotic syndrome occurring in a patient with documented obstructive sleep apnea syndrume.

The diagnosis of both the obstructive sleep apnea and the nephrotic syndrome was well established in this patient. This patient had very sclere obstructive sleep apnea syndrome as evident by the frequency and duration of the apneic episodes. The patienl was spending $43 \%$ of his sleep time in an apneic state. These apneic episodes were associated with scuere hypoxemia and severe episodic pulmonary hypertension. This palient had many characteristics of nephrotic syndrome; his urine containcd $4+$ proteins. oval fat bodies and maltcse crosses. The 24 hours urine excretion of proteins was $4.5 \mathrm{C}$ which was $84 \%$ albumin on protein electruphoresis. There was no clinical or laboratory evidence of any other disease causing nephrotic syndrome.

Proteinuria has been reported in patients with Pickwickian syndrome (4-6). Many of these patients had evidence of polycythemia suggesting they had severe hypoxemia. Proteinuria improved in many patients when they lost weight. It is likely that many of these patients had sleep apnea, however, nocturnal monitoring for apneas was not performed.

Weisinger, et. $u l$, have reported four patients with massive obesity who had nephrotic syndrome. ${ }^{7}$ They suggested that obesity was responsible for the nephrotic syndrome. It is quite possible, however, that these obese patients had sleep apnea syndrome. Three of the four patients had daytime hypersomnolence, disturbed nocturnal sleep and nocturnal restlessness ail characteristics of sleep alpnea syndrome. The fourth patient had poliomyelitis. Polionyelitis has been reported to cause sleep apnea syndrome. ${ }^{8}$ Sleep studies, however. were not performed in the patients doscribed by Weisinger, et al.

Severe, episodic, nocturnal pulmonary hypertension associated with apneic episodes was well documented in our patient. Pulmonary hypertension has been described in patients with sleep apnea syndrome." "Tilkian, ef al. studied pulmonary artery" pressure in 12 men with obstructive sleep apnea during wakefulncis and sleep." Few abnormalities were present during wakefulness, but mild pulmonary hypertension occurred in five palients with exercise. During sleep, elevation of pulmonary artery pressure occurred in 10 of 12 patients and in five patients the systolic pressure exceeded $60 \mathrm{mmHg}$. Motta, tt al, studied pulmonary artery pressure in six obstructive sleep apnea patients heforc and after tracheostomy. ${ }^{10}$ Significant improvement was noted in both nocturnal pulmonary hypertension and hypoxemia in these patients following tracheostomy.

The pathogenesis of nephrotic syndrome due to sleep apneal is spexulative at the present time. Many clanges, eg hypoxemia, pulmonary hypertension. cardiac arrhythmias uccur during apneic episodes and niay cuntribute to the pathogenesis of nephrotic syndrome. Elevated renal vein pressure secondary to pulmonary hypertension may be responsible for proteinuria. Many cardinpulmonary diseases that cause sy'temic venous hypertension eg polycythemia", tricuspid valve insufficiency, 1 constrictive pericarditis, ${ }^{10}$ primary pulmonary hypertension ${ }^{14}$ have been associated with proteinuria and nephrotic syndrome. Renal venous thrombosis in an obese patient has been reported to cause nephrotic syndrome. ${ }^{15}$ Our patient did not have any clinical evidence of other renal abnormalities or thromboembolism that might suggest renal veín thrumbosis.

Another possible cause of nephrotic syndrome may be renal ischemia due to hypoxemia and/or reduced cardiac output. Severe, intermittent, nocturnal hypuxemia associated with apneic episodes occurs commonly in patients with obstructive sleep apnea. Extromely elevated pulmonary artery pressure might reduce left ventricular filling and reduced cardiac output. Evaluation of left ventricular function during apneas, however, has not been reported.

There are no studies evaluating the frequency of proteinuria and nephrotic syndrome in patients with sleep apnea syndrome. Since hypoxemia and pulmonary hypertension are common in patients with sleep apneas, renal abnormalities may also be frequent. Prospective studies are needed to evaluate the rrequency of renal abnormalities, characterize the renal histologic abnormalities and the effect of therapy for sleep apneas on proteinuria. 


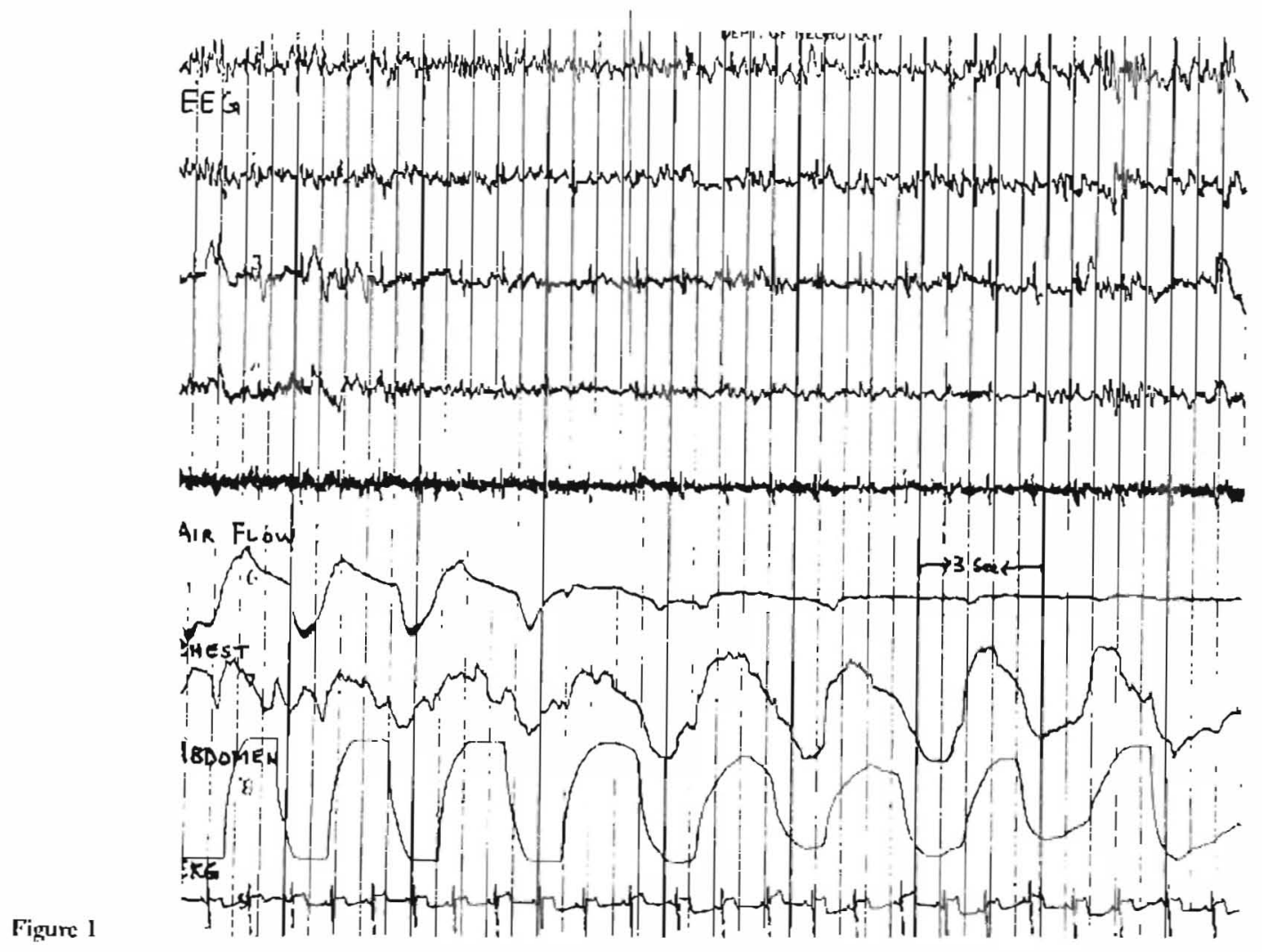

Polysomnngram consisting of EEG (line 1-5), airflow (line 6), thoraco-abdominal movements (line 7, 8 ) and EKG (line 9). After 9 seconds of airflow a 15 second obstructive apnea is seen.

\section{References}

1. Chaudhary BA, Spcir, WA: Sleep apnea syndromes. South Med J 75:39-45, 1982.

2. Chaildhary BA, Ferguson DS, Speir WA: Pulmonary edema as a presenting feature of sleep apnea syndrome. Chest 82:122-124, 1982.

3. Speir WA, Chaudhary BA: Cardiovascular consequences of sleep apnea. J Med Assoc Ga $71: 721-722,1982$.

4. Scide MJ: Heart failure due to extreme obesity report of a case with autopsy findings. $N$ Engl J Med 257: 1227-1230, 1957.

5. Weil MH: Polycythemia associated with obesity. JAMA 159: L592-1595, 1955.

6. Estes EH, Sieker HO, et al: Reversible cardiopulmonary syndrome with extreme obesity. Circulation 16:179-187, 1957.

7. Weisinger JR, Kempson RL, et al: The nephrotic syndrome: A complication of massive obesity. Ann Int Med 81:440-447, 1974.

8. Hill $\mathrm{R}$, Robbins $A W$, et al: Sleep apnea syndrome after poliomyelitis. Am Rev Mespir Dis 127:129-131, 1983 .

9. Tilkian $\Lambda G$, Guilleminault $C$, et al: Hemodynamics in sleep-induced apnea: Studies during wakefulness and sleep. Ann Int Med 85: 714-719, 1976.

10. Motta J. Guilleminault C, et al: Tracheastomy and herrodynamic changes in sleep-induced apnea. Ann Int Med 89:454-458, 1978.
11. Howenstine JA, Lee JC et al: The glomerular te sion of polycythemia, in: Proceedings of the Second International Congress of Nephrology. edited by Vostal J., Richet G. Amsterdam, EXcerpta Medica Foundation, 1964, p. 479.

12. Drummond KN, Vernier RL et al: The associated occurrence of the nephrotic syndrome and congenital heart disease. Pediatrics 31:103-114, 1963.

13. Pastor BH, Cahm M: Reversible nephrotic syndrome resulting from constrictive pericarditis. $\mathrm{N}$ Engl J Med 262:872-874, 1960.

14. Spear GS: The glomerulous in cyanotic congenital heart disease and primary pulmonary hypertension. Nephron 1:238-248, 1964.

15. Luft FC, Walker PD et al: Thrombosis of the renal veins and vena cava: occurrence is morbid obesity. JAMA 234:1158-1160, 1975.

Correspondence and reprint requests:

Bashir A. Chaudhary, M.D.

Associate Profexsor of Medicine

Section of Pulmonary and Critical Care Medicine

Department of Medicine

Medical College of Georgia

Augusta, Georgia 30912 